\title{
Role of Colposcopy in the Evaluation of Visual Inspection of Cervix with Acetic Acid-positive Cases of Unhealthy Cervix
}

\author{
${ }^{1}$ Setara B Kasem, ${ }^{2}$ Shaikh A Razzaque, ${ }^{3}$ Raisa Adiba, ${ }^{4}$ Selma Anika, ${ }^{5}$ Ferdousi Begum
}

\begin{abstract}
Introduction: Cervical cancer is the second most common cancer in women worldwide, and it is the principal cancer of women in most developing countries, where $80 \%$ of cases occur. This disease is preventable by screening and treatment of preinvasive condition. All sexually active women are at risk of acquiring a human papillomavirus (HPV) infection that may lead to cervical cancer in the future. Cervical cancer is a preventable disease as the different screening, diagnostic, and therapeutic procedures are effective. The screening procedures are visual inspection of cervix with acetic acid (VIA), Pap smear, colposcopy, and HPV deoxyribonucleic acid test. Among them, colposcopy is effective in screening, taking colposcopy-directed biopsy as well as treatment of cervical intraepithelial neoplasia $(\mathrm{CIN})$, such as cold coagulation, cryotherapy, and loop electrosurgical excision procedure. Hence, there is an obvious need to subject the women with VIA-positive report to colposcopy and directed biopsy. This study is done to evaluate the role of colposcopy in evaluation of VIA-positive cases.
\end{abstract}

Objective: Colposcopic evaluation of VIA-positive cases and detection of precancerous lesion of cervix for early management.

Materials and methods: This was a cross-sectional study done among married female patient aged 22 to 65 years, who had VIA-positive report, and attending the colposcopy clinic in the Department of Obstetrics and Gynecology of Sir Salimullah Medical College and Mitford Hospital from January 2014 to December 2016. Colposcopy-directed punch biopsy was taken from the abnormal colposcopic appearance and specimen sent for histopathological examination.

Results: Out of 97 cases, all had VIA-positive acetowhite areas. But colposcopy revealed that $76.29 \%$ had $\mathrm{CIN}$ and invasive

\footnotetext{
${ }^{1}$ Associate Professor, ${ }^{2}$ Professor, ${ }^{3}$ Honorary Medical Officer ${ }^{4}$ Student (4th Year), ${ }^{5}$ Professor and Head

${ }^{1}$ Department of Gynecology \& Obstetrics, Dhaka Medical College, Dhaka, Bangladesh

${ }^{2}$ Department of Paediatric Cardiology, National Institute of Cardiovascular Diseases, Dhaka, Bangladesh

${ }^{3}$ Department of Medicine, Dhaka Medical College, Dhaka Bangladesh

${ }^{4}$ Bangladesh Medical College, Dhaka, Bangladesh

${ }^{5}$ Department of Gynecology \& Obstetrics, Ibrahim Medical College, Dhaka, Bangladesh
}

Corresponding Author: Setara B Kasem, Associate Professor Department of Gynecology \& Obstetrics, Dhaka Medical College, Dhaka, Bangladesh, Phone: +01552314895, e-mail: dr.setaraa@gmail.com lesions, while $23.71 \%$ had either normal or inflammatory lesions. Colposcopy-directed punch biopsy revealed that $59.79 \%$ cases had positive lesions like CIN or invasive carcinoma and $40.21 \%$ had neither CIN nor invasive lesions. Among positive lesions, about $34.02 \%$ had CIN I, 3.09\% had CIN II, 0\% had CIN III, and $22.68 \%$ had invasive carcinoma. In this study, sensitivity and specificity of colposcopy examination were found 94.83 and $51.28 \%$ respectively.

Conclusion: Cervical cancer presents as major cause of morbidity and mortality, especially in developing countries like Bangladesh. In developing countries, the various screening programs are implemented for its early detection and treatment. It is evident that colposcopy plays a very important role in early diagnosis and treatment of preinvasive and early invasive carcinoma of cervix. So wide use of colposcopy in screening program of Bangladesh can reduce many young women's morbidity and mortality.

Keywords: Acetic acid-positive cases, Colposcopy, Unhealthy cervix, Visual inspection of cervix.

How to cite this article: Kasem SB, Razzaque SA, Adiba R, Anika S, Begum F. Role of Colposcopy in the Evaluation of Visual Inspection of Cervix with Acetic Acid-positive Cases of Unhealthy Cervix. J South Asian Feder Menopause Soc 2017;5(2):102-106.

Source of support: Nil

Conflict of interest: None

Date of received: 3 June 2017

Date of acceptance: 7 September 2017

Date of publication: December 2017

\section{INTRODUCTION}

Colposcopy is a diagnostic procedure to examine an illuminated magnified view of the cervix and tissues of the vagina and vulva. Many premalignant and malignant lesions in these areas have noticeable characteristics which can be detected through colposcopy. ${ }^{1}$

Cervical cancer is the commonest form of cancer in women in virtually all developing countries and is the second most common cancer in women worldwide. ${ }^{2}$ Every year, 17,686 women in Bangladesh are diagnosed with cervical cancer and 10,364 women die from the disease. ${ }^{3}$ Hospital-based data revealed that cervical cancer constitutes 22 to $29 \%$ of female cancer in Bangladesh. ${ }^{3}$ There are estimated 450,000 new cases worldwide with about 300,000 deaths each year. ${ }^{4}$ Of the new cases 
Colposcopic Evaluation of VIA-positive cases

detected, $86 \%$ occur in developing countries and $14 \%$ in developed countries. ${ }^{2}$ In developed nation, the figures for invasive cervical cancer are much lower due to adaptation of different screening tests. ${ }^{2}$

Invasive squamous cells cervical cancers are preceded by a long phase of preinvasive disease, collectively referred to as CIN. This CIN may be categorized into grades I, II, and III depending on the proportion of the thickness of the epithelium showing mature and undifferentiated cells. ${ }^{3}$ The precancerous stage is quite long and ranges from 7 to 20 years, which enables early diagnosis at this stage. ${ }^{3}$ Persistent infection with one or more of the oncogenic subtypes of HPV is necessary cause for cervical neoplasia. ${ }^{3}$ Studies have shown that HPV is responsible for more than $90 \%$ of the cases of invasive cervical cancer worldwide, and it is related to $80 \%$ of precancerous changes in the cervix. ${ }^{5}$ The risk factors for high prevalence of cervical cancer in Bangladesh are related to early marriage, early starting of sexual activities, multiparity, sexually transmitted diseases, and low socioeconomic condition. Therefore, understanding of etiological factors are important for the successful prevention of the disease. ${ }^{2}$

\section{MATERIALS AND METHODS}

This was a cross-sectional study done among married female patients who had VIA-positive report attending the colposcopy clinic in Department of Obstetrics and Gynecology of Sir Salimullah Medical College and Mitford Hospital from January 2014 to December 2016. A total number of 97 women were included in this study having age range between 22 and 65 years. Colposcopydirected punch biopsy was taken from the abnormal colposcopic appearance and specimen sent for histopathological examination.

All the patients underwent both the acetic acid and the Schiller's iodine test before they were subjected to colposcopic-directed biopsies. The biopsies were taken from the acetowhite areas and iodine negative areas.

\section{RESULTS}

Out of 97 patients, $46(47.42 \%)$ were in the age group of 26 to 35 years and 31 (31.96\%) were between 36 and 45 years (Table 1); 94 (96.91\%) patients were housewife; 24 $(24.74 \%)$ of their husband's occupation were business; and

Table 1: Age distribution of the patients

\begin{tabular}{cll}
\hline Age in years $(n=97)$ & Frequency & Percentage \\
\hline $20-25$ & 5 & 5.15 \\
$26-35$ & 46 & 47.42 \\
$36-45$ & 31 & 31.96 \\
$46-55$ & 12 & 12.37 \\
$>56$ & 3 & 3.09 \\
\hline
\end{tabular}

Table 2: Distribution of the patients by sociodemographic characteristics $(n=97)$

\begin{tabular}{lll}
\hline Variables & Frequency & Percentage \\
\hline Patient's occupation & & \\
Housewife & 94 & 96.91 \\
Day labor & 0 & 0 \\
Service & 3 & 3.09 \\
$\begin{array}{l}\text { Husband's occupation } \\
\text { Service }\end{array}$ & & \\
Business & 20 & 20.62 \\
Day labor & 24 & 24.74 \\
Driver & 13 & 13.40 \\
Agriculture & 14 & 14.43 \\
Unemployed & 10 & 10.31 \\
Abroad & 4 & 4.12 \\
Died & 4 & 4.12 \\
Yearly family income (Taka) & 8 & 8.25 \\
$<10,000$ & 7 & \\
10,000-20,000 & 75 & 7.22 \\
$21,000-30,000$ & 6 & 77.32 \\
$31,000-40,000$ & 0 & 6.19 \\
$>41,000$ & 9 & 0 \\
\hline
\end{tabular}

$20(20.62 \%)$ were doing service. The yearly family income of $75(77.32 \%)$ patients was 10,000 to 20,000 (Table 2 ).

Regarding the risk factors, 21 (21.65\%) patients were married before the age of 15 years and 72 (74.23\%) were married between the age of 15 and 20 years; 67 (69.07\%) patients had their first child before the age of 20 years; 41 $(42.27 \%)$ of them had 3 to 4 children (Table 3 ).

The findings on colposcopy showed out of 97 VIApositive patients, $3(3.09 \%)$ had normal colposcopic findings. Colposcopy showed inflammation of cervix in 20 (20.62\%) cases, CIN I in 45 (46.39\%) cases, CIN II in 12 $(12.37 \%)$ cases, CIN III in $4(4.12 \%)$ cases, and invasive cervical carcinoma in $13(13.40 \%)$ cases (Table 4$)$.

Later on, histopathology of biopsy showed normal findings in 5 (5.15\%) cases, inflammation in 34 (35.05\%)

Table 3: Distribution of study subjects according to risk factors of cervical cancer $(n=97)$

\begin{tabular}{lll}
\hline Variables & Frequency & Percentage \\
\hline Age of marriage & & \\
$<15$ & 21 & 21.65 \\
$15-20$ & 72 & 74.23 \\
$>20$ & 4 & 4.12 \\
Age of first child & & \\
$<15$ & 4 & 4.10 \\
$\quad 15-20$ & 67 & 69.07 \\
$>20$ & 24 & 24.74 \\
Number of children & & \\
No children & 2 & 2.06 \\
$1-2$ & 38 & 39.18 \\
$3-4$ & 41 & 42.27 \\
$>4$ & 16 & 16.49 \\
Abortion & 19 & 19.59 \\
Menstruation regulation & 17 & 17.53 \\
\hline
\end{tabular}


Table 4: Distribution of study subjects according to colposcopic findings

\begin{tabular}{lll}
\hline Findings & Number $(n=97)$ & Percentage \\
\hline SCJ visualized & 87 & 89.69 \\
SCJ not visualized & 10 & 10.31 \\
AW lesion present & 97 & 100 \\
Normal & 3 & 3.09 \\
Inflammation & 20 & 20.62 \\
Colposcopy negative & 23 & 23.71 \\
CIN I & 45 & 46.39 \\
CIN II & 12 & 12.37 \\
CIN III & 4 & 4.12 \\
Invasive cervical carcinoma & 13 & 13.40 \\
Colposcopy positive & 74 & 76.29 \\
\hline AW: Acetowite; SCJ:Squamocolumar
\end{tabular}

AW: Acetowhite; SCJ: Squamocolumnar junction

cases, CIN I in $33(34.02 \%)$ cases (Fig. 1), CIN II in $3(3.09 \%)$ cases, CIN III in $0(0 \%)$ case (Fig. 2$)$, and invasive squamous cell carcinoma in $22(21.68 \%)$ cases (Table 5).

Among the negative colposcopicay findings ( 23 cases) biopsy shows CIN I in 1 case and invasive carcinoma in 2 cases and among the positive colposcopy findings

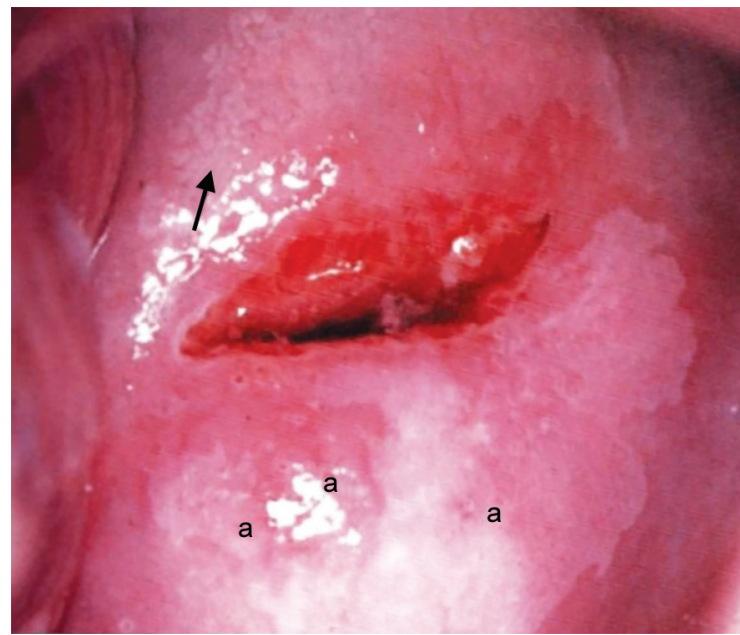

Fig. 1: Dense acetowhite VIA positive lesion with fine mosaic pattern indicating low grade (CIN I) lesion
Table 5: Histology results of biopsy findings

\begin{tabular}{lll}
\hline Biopsy findings & Number $(n=97)$ & Percentage \\
\hline Normal & 5 & 5.15 \\
Inflammation & 34 & 35.05 \\
Biopsy negative & 39 & 40.21 \\
CIN I & 33 & 34.02 \\
CIN II & 3 & 3.09 \\
CIN III & 0 & 0 \\
Invasive carcinoma & 22 & 22.68 \\
Biopsy positive & 58 & 59.79 \\
\hline
\end{tabular}

(74 cases) biopsy shows 5 normal and 34 inflammation (Table 6).

Table 7 shows among the 58 biopsy positive cases 55 cases are colposcopically positive and 3 are colposcopically negative. Among the 39 biopsy negative cases 20 cases are biopsy negative and19 cases are biopsy positive.

\section{Sensitivity and Specificity Analyses}

As all cases were VIA positive, the sensitivity and specificity of VIA could not be analyzed. But the sensitivity

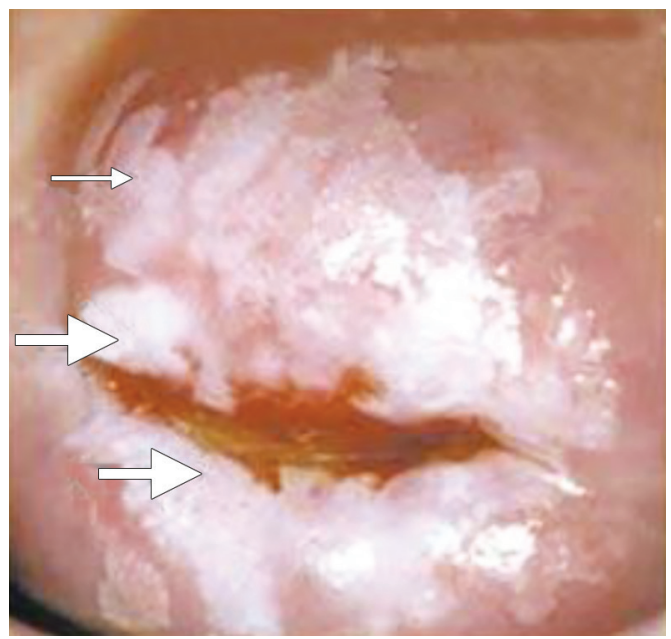

Fig. 2: Dense, opaque,thick acetowhite area, coarse punctuation and mosaicism indicating CIN III lesion

Table 6: Comparative findings of colposcopy and colposcopy-directed biopsy of VIA-positive cases

\begin{tabular}{|c|c|c|c|c|c|c|}
\hline \multirow{2}{*}{$\begin{array}{l}\text { Colposcopy findings of all } \\
\text { VIA-positive cases }(n=97)\end{array}$} & \multicolumn{6}{|c|}{ Colposcopy-directed biopsy findings } \\
\hline & Normal & Inflammation & CINI & CIN II & CIN III & Invasive carcinoma \\
\hline Colposcopy & 4 & 16 & 1 & & & 2 \\
\hline \multicolumn{7}{|l|}{ Negative (23) Normal (3) } \\
\hline \multicolumn{7}{|l|}{ Inflammation (20) } \\
\hline \multicolumn{7}{|l|}{ Colposcopy } \\
\hline \multicolumn{7}{|l|}{ Positive (74) } \\
\hline CIN I (45) & 1 & 17 & 26 & 1 & & \\
\hline CIN II (12) & & 1 & 6 & 1 & & 4 \\
\hline CIN III (4) & & & & 1 & & 3 \\
\hline Invasive & & & & & & 13 \\
\hline \multicolumn{7}{|l|}{ Carcinoma (13) } \\
\hline Total & 5 & 34 & 33 & 3 & 0 & 22 \\
\hline
\end{tabular}


Colposcopic Evaluation of VIA-positive cases

\begin{tabular}{llll}
\multicolumn{2}{l}{ Table 7: Sensitivity and specificity of colposcopy in detecting CIN } \\
\hline Colposcopic findings & Disease positive & Negative & Total \\
\hline Positive & 55 & 19 & 74 \\
Negative & 3 & 20 & 23 \\
Total & 58 & 39 & 97 \\
\hline
\end{tabular}

and specificity of colposcopy were calculated considering colposcopy-directed biopsy as a gold standard. ${ }^{2}$ Among the VIA-positive cases, $76.29 \%$ were positive in colposcopy and $59.75 \%$ positive in biopsy. The sensitivity and specificity of colposcopy were 94.83 and $51.28 \%$, respectively, as shown in Table 8 .

\section{DISCUSSION}

Colposcopy, a clinical method of proven accuracy, is an excellent means of evaluating clinically unhealthy cervix. ${ }^{6}$

In this study, the peak age group $(47.42 \%)$ of VIApositive cases was 26 to 35 years with a mean age of 30.74 years. Almost two-thirds of the cases were within 26 to 45 years. As the age advanced, the percent of age group reduced according to this study. Tofazzal et $\mathrm{al}^{10}$ found highest incidence of years in age group closely followed by 30 to 40 years, where the age of occurrence of invasive cervical cancer was 40 to 45 years. ${ }^{7}$ Jahan's findings correspond well with this study ${ }^{8}$ and it is indicative that CIN is more prone to occur in sexually active women. World Health Organization ${ }^{9}$ also suggested the priority age group as 35 to 45 years for the screening of CIN. ${ }^{9}$

The occupational status expressed that housewives (96.91\%) were affected predominantly. Their husband's occupation were predominantly business, service, driver, and day laborer. Socioeconomic status had always been playing an epidemiological role in genesis of dysplasia. ${ }^{10}$ In our study, $77.32 \%$ of the respondent's yearly family income was 10,000 to 20,000. Regarding the age of marriage, $74.23 \%$ got married at 15 to 20 years of age, which corresponds with the study of Rotkin $\mathrm{ID}^{11} ; 69.07 \%$ of the women had their first child at 15 to 20 years; $42.27 \%$ of the women had 3 to 4 children, indicating multiparity as a related risk for $\mathrm{CIN}$ of the cervix. This observation correlates with the study of Schiffman et al and Rotkin ID. ${ }^{11,12}$ Smith believes that poor obstetrical and postpartum care and neglect of the symptoms of a lacerated and ulcerated cervix accounts for the (Mary and Daly, 1993) greater frequency of cervical cancer among the poorer classes (Jussawalla and Vole, 1987). ${ }^{13,14}$

In our study, out of 97 cases, all had VIA-positive acetowhite areas. But colposcopy revealed that $76.29 \%$ had CIN and invasive lesions, while $23.71 \%$ had either normal or inflammatory lesions. Colposcopy-directed punch biopsy revealed that $59.79 \%$ cases had positive lesions like CIN or invasive carcinoma and $40.21 \%$ had neither CIN nor invasive lesions. Evidence of CIN and invasive
Table 8: Accuracy of colposcopy for screening by statistical analysis

\begin{tabular}{ll}
\hline Colposcopy test accuracy & Result \\
\hline True positive & 55 \\
False positive & 19 \\
True negative & 20 \\
False negative & 3 \\
Sensitivity & $94.83 \%$ \\
Specificity & $51.28 \%$ \\
Positive predictive value & $74.32 \%$ \\
Negative predictive value & $86.96 \%$ \\
\hline
\end{tabular}

lesions in colposcopy-directed cervical biopsy among the VIA-positive patients strongly suggested the need of VIA as an essential screening test. A high number of cases on histopathological examination were those of infection and among them majority had chronic cervicitis (35.05\%).

Within 97 VIA-positive cases, 74 cases $(76.29 \%)$ had positive findings by colposcopy and 58 cases (59.79\%) had positive findings by biopsy. True positive cases were 55 and true negative cases were 20. False positives were 19 and false negatives were 3 . In this study, sensitivity and specificity of colposcopy examination were found to be 94.83 and $51.28 \%$ respectively. Many studies have reported sensitivity of colposcopy as 87 to 99,96 , and $94.4 \%$, which is comparable to our study. ${ }^{15-17}$ Specificity of colposcopy in our study was consistent with many studies, which reported specificities of 26 to 87, 57, 50, and $46.42 \% .15,17-19$ High sensitivity but low specificity of colposcopy may be due to high incidence of unsuspected acetowhite epithelium, which might be due to inflammation, immature metaplasia, and latent $\mathrm{HPV}$ infection..$^{20} \mathrm{In}$ our study, positive predictive value is $74.32 \%$ and negative predictive value is $86.96 \%$.

The limitation of colposcopy is its dependence on observer variability and relatively weaker performance in differentiating normal cervix from low-grade lesions. ${ }^{20}$ The colposcopic diagnosis of CIN requires an understanding and recognition of four main features: Color tone, intensity of acetowhitening, margins and surface contour of acetowhite area, vascular pattern, and iodine staining. Variations in quality and quantity of these atypical appearances help in differentiating CIN from other lesions and between grades of $\mathrm{CIN} .^{21}$

\section{CONCLUSION}

Cervical cancer continues to be a major public health problem that kills approximately a quarter of million women every year and affects developing countries and young women in particular. ${ }^{22}$ Cervical cancer occurs at a relatively young age, resulting in proportionally more life-years lost, compared with other major cancers. Agespecific analysis clearly indicates that cervical cancer primarily affects young adult women who are actively 
involved in their careers or caring for their families. ${ }^{22}$ It is evident that colposcopy plays a very important role in early diagnosis and treatment of preinvasive and early invasive carcinoma of cervix. So wide use of colposcopy in screening programs of Bangladesh can reduce many young women's morbidity and mortality.

\section{REFERENCES}

1. Akhter S, Bari A, Hayat Z. Variability study between Pap smear, colposcopy and cervical histopathology findings. J Pak Med Assoc 2015 Dec;65(12):1295-1299.

2. Begum KS, Sultana K, Begum RA. Result of colposcopy among VIA positive cases attending in colposcopy clinic of BSMMU. J Med Sci Res 2014 Jan;22(1):15-22.

3. Banik M, Akhter SN, Kasem SB. Role of colposcopy for the detection of precancerous lesion of cervix in a medical college hospital. ICMH J 2016;7(1):15-19.

4. Qureshi A, Rather S, Bhagat P. Screening for cervical carcinoma by VIA. Internet J Gynecol Obstet 2012;16(2):1-5.

5. Wrong LP, Wrong YL, Low WY, Khoo EM, Shuib R. Knowledge and awareness of cervical cancer and screening among Malaysian women who have never had a Pap smear: a qualitative study. Singapore Med J 2009 Jan;50(1):49-53.

6. Ramesh G, Sudha R, Jayashree AK, Padmini J. Colposcopic evaluation of the unhealthy cervix. J Clin Diagn Res 2012 Aug;6(6):1026-1028.

7. Tofazzal N, Khan SR, Islam B, et al . Study of the association of human papilloma virus with cervical cancer and precancerous lesions in a group of Bangladeshi women. J Bangladesh College Physicians Surgeons 1994;12:85-88.

8. Jahan Y. Colposcopic findings of VIA positive gynaecological cases of BSMMU. Dissertation submitted to BCPS, 2005.

9. World Health Organization. Human papilloma virus and cervical cancer (Summary report), Bangladesh. Updated year 2007.

10. Nayani ZS, Hendre PC. Comparison and correlation of Pap smear with colposcopy and histopathology in evaluation of cervix. J Evol Med Dent Sci 2015 Jul;4(53):9236-9247.

11. Rotkin ID. A comparison review of key epidemiological studies in cervical cancer related to current searches for transmissible agents. Cancer Res 1973 Jun;33(6):1353-1367.
12. Schiffman $M$, Herrero R, Hildesheim A, Sherman ME, Bratti M, Wacholder S, Alfaro M, Hutchinson M, Morales J, Greenberg $\mathrm{MD}$, et al. HPV DNA testing in cervical cancer screening. Results from women in a high-risk province of Costa Rica. JAMA 2000 Jan;283(1):87-93.

13. Mary, B.; Daly, MD. Epidemiology of cancer. In: Weiss, GR. (Ed.) Clinical oncology-a large medical book. 1st ed. San Antonio, TX: University of Texas Health Sciences Center; 1993.

14. Jussawalla, DJ. Epidemiology of carcinoma of the cervix in India. In: Mould, RF.; Bose, A. (Eds.) Carcinoma of the cervix in developing areas. Bristol and Philadelphia: Adam Highler; 1987.

15. Olaniyan OB. Validity of colposcopy in the diagnosis of early cervical neoplasia—a review. Afr J Reprod Health 2002 Dec;6(3):59-69.

16. Zarchi MK, Binesh F, Kazemi Z, TeimooriS, Soltani HR, Chiti Z. Value of colposcopy in the early diagnosis of cervical cancer in patients with abnormal Pap smears at Shahid Sadaoughi Hospital, Yazd. Asian Pacific J Cancer Prev 2011;12(12): 3439-3441.

17. Adamopoulou M, Kalkani E, Charvalos E, Avgoustidis D, Haidopoulos D, Yapijakis C. Comparison of cytology, colposcopy, HPV typing and biomarker analysis in cervical neoplasia. Anticancer Res 2009 Aug;29(8):3401-3409.

18. Zivadinovic R, Radovic M, Lilic V, Petric S. Grading the severity of preinvasive changes of the uterine cervix by colposcopy and exfoliating cytology. Med Biol 2005;12(1):55-59.

19. Ramesh G, Sudha R, Jayashree AK, Padmini J. Colposcopic evaluation of the unhealthy cervix. J Clin Diagn Res 2012 Aug;6(6):1026-1028.

20. Tapasvi I, Tapasvi C, Aggarwal A, Aggarwal AK. The role of colposcopy, colposcopically directed biopsies and cytology in the evaluation of unhealthy cervix. Indian J Basic Appl Med Res 2015 Jun;4(3):150-158.

21. Jesmin ZF, Khanam A, Saha E, Hossain M. Clinical effectiveness of VIA and colposcopy based management of cervical intraepithelial neoplasia. Bangladesh Med J (Khulna) 2014;47:16-20.

22. Arbyn M, Castellsague $X$, Sanjose S de, Bruni L, Saraiya M, Bray F, Ferlay J. Worldwide burden of cervical cancer in 2008. Ann Oncol 2011 Dec;22(12):2675-2686. 